\title{
Anti-Radiation Missiles vs. Radars
}

\author{
Stanisław Czeszejko
}

\begin{abstract}
In this article the author makes an attempt to characterize the factors which are to be taken into consideration while designing the ground radar component of Air Defense systems, in order to enable them to operate on the modern battlefield. He presents the latest theoretical views on the relationship between the usage of anti-radar weapons and the organizational and technical defense mechanisms which can be deployed against such weapons. In particular the author emphasizes the protection of radars against anti-radiation missiles (ARMs) which present the biggest threat for effective Air Defense systems. He also stresses the need to combine radars into one system which enables the streamlining of their work parameters and thus ensuring their complex usage. The gaining of those capabilities will guarantee that the parameters of the air surveillance radar zone can be defined effectively.
\end{abstract}

Keywords-anti-radiation missiles, radar, radiolocation, air defense system, survive to operate on the battlefield

\section{Anti-Radiation Missiles}

$\mathbf{S}$ INCE the middle of the $20^{\text {th }}$ century radars have been destroyed by specialized weapons - anti-radiation missiles, homing in on the electromagnetic radiation of the radars. Over the decades the radars have been modified and modernized. New ones have been constructed and different exploitation techniques have been developed. The technical progress of these devices is a never-ending competition.

The anti-radiation missiles destroy radars which are elements of the opponent's air defence system, this in turn allows for the free operating of friendly aircraft within the enemy's airspace and then also, during combat within the opponent's territory, their targets are also various objects located there. In the first case, aircrafts carrying these missiles attempt to fulfil the task without entering the striking distance of the ground elements of the enemy's air defence system (rockets and barrel artillery). Such operations demand proper evaluation of the space striking abilities of the system and to ensure the system is equipped with weapons of the proper strike range needed for destroying the defence system elements. In the second case, the air defence system elements are attacked while crossing the border of their strike range. Also, the weapons systems protecting important objects within the opponent's territory are eliminated.

While estimating the influence of the anti-radiation missiles' strike range one cannot neglect the inseparable parameter of the missile flight speed. These two parameters determine the time in which the missile reaches the target after being launched from the plane. Table 1 presents the simplified data concerning the speed, range and flight time of the chosen antiradiation missiles, which shall be discussed in more detail further on. Anti-radiation missiles can be divided roughly

S. Czeszejko is with the Air Force Command, Żwirki i Wigury Str. 103, 00-912 Warsaw, Poland (e-mail: staszejko@poczta.onet.pl). according to their range into short range missiles (maximum $100 \mathrm{~km}$ ), mid-range missiles (maximum $200 \mathrm{~km}$ ) and long range missiles (over $200 \mathrm{~km}$ ).

Another important parameter of the anti-radiation missiles is the efficiency of target damage done by the warhead exploding, this is significant for the radar's survival on the battlefield. In the 1950s the low target accuracy of the anti-radiation missiles was compensated by using warheads of high explosive power, large enough for strategic aircrafts to carry them. During the 1960s three new weight categories of warheads appeared (approximately $150 \mathrm{~kg}, 86-90 \mathrm{~kg}$ and $66 \mathrm{~kg}$ ); these are still in use with just a few exceptions. In comparison with the former generation of missiles, their higher accuracy and probability of hitting the target allowed for achieving expected striking efficiency in each of these categories. In addition, the distance (altitude) of the fuse from the target was optimized. Such was the situation until the beginning of the 1990s, when the British ALARM missile appeared, whose efficiency is proved by the possibility of attacking a radar with a within 1 meter accuracy (without GPS). For example, the AGM-45 Shrike missile (with approximately a $66 \mathrm{~kg}$ warhead) was striking the radars within 15 meters range, and its A version was equipped with highexplosives containing 20000 cubic piercing fragments (while hitting the target directly or imprecisely with this missile a high striking effect could be achieved), while the Ch-58USzE missile (with an approximate $150 \mathrm{~kg}$ warhead) could hit radars within a range of 20 meters. The target accuracy of the Ch$15 \mathrm{P}$ and Ch-58USzE missiles is $5-8$ meters, of the Ch-31P missile up to 5-7 m, and of the AGM-88 A/B HARM missile the target accuracy is estimated as between 7.3-9 m. Also, for the Ch-58USzE missile the target hitting probability within the range of 20 meters is 0.8 . The AGM-88C HARM warhead is equipped with 12845 tungsten cubes $(5 \mathrm{~mm})$, able to perforate a $12.7 \mathrm{~mm}$ thick soft metal sheet or a $6.35 \mathrm{~mm}$ thick armoured plate from a distance of 6 meters, maintaining the missile's target accuracy. The German ARMIGER missile has quite a small warhead, only $20 \mathrm{~kg}$, and its target accuracy is less than 1 meter $(\leq 1 \mathrm{~m})$. Probably the target accuracy of the American AGM-88E AARGM missile is on a similar level to that of the ARMIGER missile $(\leq 1 \mathrm{~m})$; since both of them are based on the same construction (AGM-88D HARM) and both represent the same technological advancement level.

But in order to deploy the missile within the efficient strike range it must be equipped with a proper guidance system. Missiles produced in the 1950s and 1960s were homed to the electromagnetic radiation of the radars with support of the inertial guidance system only. The whole process was controlled by a technologically simple autopilot. In the 1970s the dynamic development of miniature transistor-circuit systems began, and they were also employed by the constructors of the anti-radiation missiles homing systems. The following two 
decades were characterised by the improvement of the existing electronics of the missiles, the aim being the possibility of constructing devices equipped with programmable data bases. They allowed for the comparison of the parameters of detected radars and thus the ability to choose those most dangerous or those which have been pre-defined - as a the specifics of a given combat task demanded. In addition, the contractors increased the possibilities of eliminating jammers, i.e. the sources of purposeful electromagnetic disturbance and thus improved the missiles' exploitation flexibility.

A conventional anti-radiation missile is homed primarily to the radar's mainlobe emission, but also to the emission of its horizontal sidelobes and the backlobes emission - it depends on the distance between the radar and the missile. However, in the case of the older radars the primary target is their horizontal sidelobes and backlobes emission of a very high level, which radiate continually. This allows the missile to have uninterrupted tracking of the radar and the passive antiradiation homing receiver does not become saturated. Modern radars with a very low level of the horizontal sidelobes and backlobes emissions are a "blinking" target for a missile, and the "blinking" is the result of the intervals in receiving the radar mainlobe emission during the turn of its antenna. In such a situation, the on-board systems of missiles without GPS are forced to estimate the radar's position on the basis of an intermittently received emission. When the turn speed of the antenna is low (long intervals in receiving the emission), the guidance system of the missile is supported by its inertial system, especially during the final phase of flight, which often results with a bigger margin of error (a few meters) in detecting the position of the radar than was assumed beforehand. The error is usually increased to such an extent that in the moment of directly hitting the target the warhead is not set off by a contact fuse but by a proximity fuse. In order to maintain the attack efficiency, the warhead must be equipped with a much stronger explosive.

In 1973, during the Israeli-Arabian Yom Kippur War, conventional anti-radiation missiles of the 1950s' generation were used. At that time, Egyptian Tu-16 bombers fired $13 \mathrm{KSR}-2$ and $12 \mathrm{KSR}-11$ (KSR-2P) missiles from above the Mediterranean towards the targets located on the coast and inside Israeli territory. Most of the missiles (about 20) were intercepted and destroyed by either the air force or the HAWK surface-to-air missiles. 5 of them penetrated through the Israeli air defence system and reached their designated targets. Three radars and one logistic point on the Sinai Peninsula were eliminated. Missiles of the 1970s' generation were used during the Iraqi-Iranian war (1980-1988) by the Iraqi aircrafts which were targeting Ch-28 missiles towards the radars of the Iranian HAWK systems. Effects of these attacks have not been revealed, unlike the results of the Ch-22MP BURJA missiles which were launched from the Iraqi Tu-22K bombers. Despite numerous launchings towards the HAWK radars, only one missile hit its target. The reason was the poor training of the Iraqi bomber crews, the low efficiency of the guiding system (on the missiles and the deck systems of the bombers), as well as difficulties in efficiently detecting the radars' position from a long distance. Therefore, later the launchings took place at a distance of $60 \mathrm{~km}$ or less and the missiles were carried by the Tu-16 bombers. The targets attacked were mainly located near Teheran: oil refineries and other cities protected by the anti-aircraft system of Iran. The missiles of the 1980s' generation were used for the first time on 15th April 1986 during the US bombing of Libya (Tripoli and Benghazi), code-named "Operation El Dorado Canyon". AGM-88A Harm anti-radiation missiles were homed very efficiently eliminating the radars of Libyan air defence system rocket launchers (SA-2 GUIDELINE or S-75 DZWINA, SA-3 GOA or S-125 PECZORA and SA-5 GAMMON or S-200 ANGARA) located around the Gulf of Sidra [1].

In the 1990s the British ALARM missile appeared, introducing some changes in the context of fighting radars. ALARM can be used in the same way as the conventional missiles constructed so far, but in addition it is able to detect and destroy radars independently. It climbs to an altitude of 12000-21000 meters within the task zone [2]. There its engine is turned off, the parachute opens and the missile starts diving slowly, while its passive anti-radiation homing receiver searches for the target - an operating radar. When such is detected, the parachute detaches itself and due to gravity the missile - directed by the guidance system - moves towards the radar. The ALARM missile was created before GPS started to be used in such constructions and its operating method has its reasons. The so called vertical attack of this missile is a result of an assumption that had been made before even the ALARM project appeared. The passive anti-radiation homing receiver of this missile independently homes itself towards the radar emission radiating vertically up, i.e. towards the vertical sidelobes. Since most of the radars became able to locate the air objects with high accuracy, the emission level of the horizontal sidelobes and backlobes have lowered, in comparison to high emission level of the vertical sidelobes. Regardless of the direction of the mainlobe emission of the radar, the ALARM passive anti-radiation homing receiver is able to track continuously the fluctuating microwave emission leaking upward from the radar's antenna.

Guiding to the vertical sidelobes (vertical attack at an angle of $90^{\circ}$ ) has an additional aspect, namely reducing the influence of emission coming from radiation reflected by the ground objects, which in case of attack at an angle of $20^{\circ}$. $40^{\circ}$ normally widens the margin of error. Taking advantage of it, the ALARM missile is able to attack the target with high accuracy. Moreover, the accuracy is 1 meter, i.e. the explosion should be initiated in the distance of 1 meter from the radar antenna, which increases its most explosive power. The programmable warhead of this missile can have a data base containing information on the general construction of every type of radar, which show, among other details, the place where the antenna is located. This enables the missile to initiate a precise explosion destroying the antenna system or the main electronic systems located in the main blocks of the radar's board (it depends on what task has been programmed before). It is of special importance in case of eliminating radars whose antennas are raised high, designed for detecting also air objects flying at low altitude. It must be emphasized that the warhead of an anti-radiation missile equipped with smaller 
explosive exploding very close to the antenna will result in the same destruction level as a warhead with bigger explosive exploding at a greater distance.

Such missiles were used for the first time during the First Gulf War (1990-1991). 121 ALARM missiles were launched from British TORNADO aircraft, which carried out 24 mission aimed only at destroying the air defence system of Iraq and 52 SEAD missions (Suppression of Enemy Air Defences), operating within the opponent's airspace. In a few cases the launching of the ALARMs of the first experimental series were unsuccessful [2]. In order to eliminate the Iraqi air defence system elements, the coalition forces used also HARM antiradiation missiles. During the "Desert Storm" operation about 2000 of these were launched at the Iraqi radars [3]. A question might be asked as to whether Iraq really had so many air defence radars. However, one can conclude that these missiles were used on many occasions only preventively. Some sources prove that the initiators of such launchings were mainly the pilots of the US Navy (F/A-18 planes), who were using an imprecise warning system - the first version of ALR-67 RWR [4], while the crews of aircrafts designed especially for the SEAD missions, carried out well planned selection, had more time for destroying their targets (it is their main task); they were also better trained and equipped, with much better electronics.

During the First Gulf War ALARM missiles, climbing vertically, were a novelty for many allied pilots. Quite often the missiles speeding upwards (aiming at reaching maximum speed and starting the parachute dive) were mistaken for Iraqi air defence system rockets, which would alarm the battle group unnecessarily, with accounts of such events becoming transformed into various anecdotes.

The analysis of the conflict of the 1990s and experiences resulting from it led to the upgrading of some of the missiles by equipping their guidance systems with additional elements. One of the most important experiences came from the period of NATO operating over the Balkan peninsula. During the NATO air operation called "Deliberate Force" of 1995, American AGM-88 HARM missiles of the first versions were used. In addition the American F-16 aircraft were already then equipped with the Harm Targeting System (HTS), which was used then for the first time in a combat environment. During the 1999 period of this conflict ALARM, AGM-88B HARM and AGM-88C HARM missiles were launched over Serbia and Kosovo, but they were not able to do serious damage to the extremely mobile Yugoslavian air-defence forces. The damages were symbolic and resulted from the too low accuracy of the inertial guiding systems homing the missiles. This provided a strong impulse for the development and later use of GPS in the guidance systems.

In the 1990s, during the Balkan conflict, NATO planes launched altogether 743 HARM missiles, 6 ALARMs and 8 ARMATs towards the radars of the Yugoslavian air defence forces. However, only about 115-130 of the ground targets emitting electromagnetic radiation were attacked, which proves the high efficiency of the Yugoslavian forces' operations, i.e. the high discipline level concerning the limited time of radars' radiation (up to 10 seconds) and the high mobility of the forces (constantly changing the positions of the anti-aircraft weapons). The NATO official reports state that the efficiency of the HARM missiles was 3\%-6.6\%, depending on the operation's phase [5]. The high efficiency of the Yugoslavian forces was proved by the fact that during the operations the Americans decided to deploy to Italy their experimental Tiger Team from China Lake Weapons Division (USA), an institution testing new weapons. During just 36 days, its pilots tested over 400 HARM missiles, in order to develop new tactics for launching them, allowing for increased efficiency. The effects of their work were instantly transferred to the US Navy units. As a result, immediately more of the attacked objects were destroyed [6].

By the year 2000 the US Air Force and US Marine Corps (USMC) had taken procession of over 19600 AGM-88 Harm missiles of different versions, while by 1997 the German Bundeswehra bought for the Luftwaffe (German Air Force) and Marineflieger (German Naval Air Force) exactly 1000 Harm missiles.

The best known military conflict of the first decade of the $21^{\text {st }}$ century, during which anti-radiation missiles were used, was the Second Gulf War of 2003. The elements of the Iraqi air defence system were being then destroyed by, among others, the HARM missiles - over 400 of them were launched towards all kinds of Iraqi radars [7]. Taking into account the economic situation of Iraq and its low possibilities of recreating its air defence system after the war of 1990-91 and various subsequent air operations (e.g."Desert Fox"), the number of launched antiradiation missiles might seem too large, especially that they were better developed technologically and also the AGM-88C HARM missiles were already accessible. At that time, the American planes were already equipped with an instrument for launching the anti-radiation missiles for self-protection, and probably this function was used excessively by the crews of the combat planes carrying such missiles.

The most recent military conflict, during which the antiradiation missiles were used, was the war in the Southern Ossetia of 2008 (Georgia's forces vs. combined forces of Southern Ossetia, Abkhazia and Russia). At that time, the basic equipment of the Georgian radar forces was a few ST68U (36D6-M) radars of Soviet production; they were quite difficult to be manoeuvred. In a relatively short time, the Russian air forces managed to eliminate all Georgian radars.

All the above-mentioned experiences triggered further development. The first decade of the $21^{\text {st }}$ century was a period of intensified development of the guidance systems homing the anti-radiation missiles towards the radars. These systems became equipped with GPS: American AGM-88D HARM and AGM-88E AARGM missiles, German ARMIGER missiles and Israeli STAR-1 missile. In addition, ARMIGER was also equipped with an Infrared sensor, providing a picture processed by a special system. Probably, this was caused by the fact that earlier the German TORNADO.ECR, specialized aircraft equipped with such sensors, were able to lower the electromagnetic emission of the plain's board. But it was the configuration of the AGM-88E AARGM missile that was subject to greatest modification. This missile does not have an Infrared sensor, but it is equipped with active millimetre wave 
radar with an extremely precise Doppler modulator (active radar seeker), which increased the possibilities of fighting both stationary and mobile targets (e.g. a radar changing position after being turned off). Also, this missile contains a system for information exchange via radio [8] (used for updating the data on the radar for the missile - as a part of targeting - and in order to transfer information about the radar being fought, recorded just before the moment of explosion of the missile hitting the target). The systems built in the AGM-88E AARGM missile allow its own millimetre wave radar to fully cooperating with the digital passive receiver of electromagnetic waves [9]. This makes the radar operator unable to stop the missile's attack on the radar by turning it off, changing its combat position or turning on a decoy - a radar electromagnetic trap imitating the radar's signal meant to attract the missile away from the real radar, i.e. creating a false location of the attacked radar. The head of the millimetre wave radar is meant to track the location of the attacked radar in a way which allows the missile to hit the real radar and not the false source of emission (decoy), even if the radar would start to move. Also, it is worth mentioning a slightly different type of anti-radiation missile, namely the American AGM-136 TACIT RAINBOW and Israeli STAR-1 missiles. They are in fact cruise missiles, in which the warhead is built into the vehicle and which after being launched travel in front of the air strike force following a pre-programmed flight path. Their task is to destroy the anti-aircraft radars located in the planes flight path.

The second decade of the $21^{\text {st }}$ century brought only scant promises for the construction of new missiles, regardless of the fact that the scientists of many states must be working on new technical solutions. In 2012 it was announced that new Russian anti-radiation missiles shall have the same possibilities which already characterize their existing Western counterparts. The code of the Ch-31PD missiles (probably produced in 2003) reveals only their serious modernization (mainly of the warhead), which shall be surely based on the exploitation of the satellite guiding homing systems. Obviously, it may be expected that because of the expected export, the Russians will not use the Russian Glonass satellite system exclusively and they also will produce a missile version using the Western GPS system. Of course, applying a completely new technical guiding solution cannot be excluded (e.g. the German ARMIGER - additional use of Infrared sensor). In the case of a solution similar to the AGM-88E AARGM (additional active millimeter wave radar), the basis of such a construction can be a warhead of an already existing missile (e.g. Ch-15S, Ch-25MAE or Ch-58A). Time shall show the direction of Russian military technological development [10].

Evaluating the development of the existing anti-radiation missiles, one could single out a few main ways of fighting radars:

- direct attack - a missile launched usually at a middle or long distance climbs to a great altitude (e.g. for Ch$32 \mathrm{P}$ it is 22000 meters), then accelerates, achieving its maximum speed in the final phase of the flight, denying thus the radar crew the ability to react to the attack. The target may be hit at a classical angle (like most missiles, between $20^{\circ}$ and $\left.40^{\circ}\right)$ or vertically $\left(90^{\circ}\right.$ - ALARM missile);

- shallow dive trajectory attack - the missile is usually launched from a short distance, it attacks the radar in a shallow dive trajectory, and it does not achieve maximum height, moving with optimal cruise speed;

- delayed attack - the missile may be launched at any height, it reaches its maximum height, then turns off the engine and starts diving with a parachute, which detaches after detecting the radar; then the missile due to gravity falls down, homing towards the target (vertical attack at an angle of $90^{\circ}$, performed nowadays only by the British ALARM missile - so called "loiter mode");

- manoeuvring attack - a cruise anti-radiation missile built as a plane (it can be manoeuvring in a defined area and waiting for a radar to be turned on), and its main task is destroying the anti-aircraft radars located in the planes flight path (e.g. American AGM-136 TACIT RAINBOW or Israeli STAR-1 missiles).

The construction of modern planes and the modernizing of them is nowadays aimed at adjusting them to simultaneous ability to carry arms from the weapons factories of the West and the East. The last operations are also forced by the companies fighting for the right to sell weapons abroad. Also, many countries have in their arsenals anti-radiation missiles from different technological eras, which results in the fact that in the field of combat any type of missile may appear.

\section{Detection and Striking Systems}

It is already possible to recognize the target and transfer this data in real time via the existing communication systems. However, there remains the question of putting this information into use for destroying the radars. However, there are already some good solutions in this context, e.g. the so called "multi-ships techniques", which mean the process in which each aircraft of the air strike force is optimally exploited [11]. A good example of this is the subsystem of F-16CJ, named HTS R7 (Harm Targeting System - HTS development version R7), which is an element of the guidance system fighting the sources of electromagnetic emission of the opponent (Joint Emitter Targeting System - JETS). It enables pilots to carry out the SEAD missions in areas strongly saturated with anti-aircraft systems, due to it being equipped with satellite navigation receivers: GPS and with elements of the data transmission system Link-16, which, combined, allow for the efficient destroying of radars not only by the anti-radiation AGM-88 HARM missiles, but also by Precision Guided Munition - PGMs.

Also, for the planes of the next generation (e.g. F/A-18) a newer Target Acquisition System (TAS) was developed. Moreover, during a radar fighting operation numerous types of bombs can be used (diving gravitationally) and missiles (e.g. with rocket propulsion or ramjets), guided by different systems allowing for precise homing towards the target using electromagnetic radiation (guiding by radio or active radar), infrared radiation, laser radiation, guiding by optical systems (television or electro-optical systems), satellite guiding systems or by electric signals transmitted by a cable joining the 
missile and platform (the plane or the unmanned aerial vehicle - UAV).

\section{THE MAIN QUESTION}

Which design assumptions shall enable us to avoid the effects of an anti-radiation missile attack aimed at the radar or minimize the effects of such attack?

\section{Detection}

Each radar should be equipped with an internally integrated automatic alarm system, which - in the case of detecting an attacking anti-radiation missile - will in the first instance turn off the radar (electromagnetic radiation), and subsequently the alarm system will activate a distracting device (a decoy). Next, the system will turn on a siren alarming the personnel located near the radar, and it will also send information about the type of attack to the higher command level. The alarm system should also activate other functions, which shall be described in greater detail below. Currently, in case of an attack, it is only possible to switch of the radar, activate the decoy and evacuate the radar personnel (if they are not using the remote control steering system of the radar).

\section{Time of Operating on Radar Picket}

The operating time of a radar (electromagnetic radiation) should be limited to a minimum. In battle conditions a radar's antenna must rotate in a full circle $\left(360^{\circ}\right)$ a minimum of once. In case of mid and long-range radars produced in Poland, the time of scanning the full circle differs from $2.5 \mathrm{~s}$ to $10 \mathrm{~s}$ [12], which can be shortened only by means of sector operation (electromagnetic radiation).

The total time of folding the radar consists of fractional phases: folding of the antenna, lifting the stabilizing supports, disconnecting and throwing away the cables and light pipes. At the moment, 5 minutes is the shortest time necessary for the folding of a radar produced in Poland (NUR-21, NUR-22). In order to radically shorten the process of radar folding, it is necessary to construct each mobile radar as a single vehicle, as well as equip it with automated mechanisms for the antenna "drop" (moving down), lifting the stabilizing supports, disconnecting and throwing away the cables and light pipes. Thus, it will be able to move the radar away quickly for a distance allowing the radar to survive, despite being hit by splinters coming from the explosion of an anti-radiation missile. The "drop" of the antenna should mean an immediate lowering of the antenna by the force of gravity force. The antenna should be located on a specially constructed mast and contain subassemblies allowing for the absorbing of the energy of the falling antenna strike (e.g. EPAR[13] technology, in which after the clash of two objects the kinetic energy of the fastmoving masses is absorbed by the mechanical rotary energy accumulator). The EPAR technology is based on transforming the kinetic energy of linear motion into kinetic energy of angular motion). The collapsing of the stabilizing supports can also be performed immediately and it should occur right after the "drop" of the antenna. Automatic "throwing away" of the cables and light pipes, which shall lead to the further shortening of the radar folding time, will be possible if they will all be located in one place as a multi-pipe "fast-junction". The starting and driving of the radar away must be performed automatically. The vehicle should be equipped with electric gear wheels, while the electric engine should be characterized by high torque and started by an automatic electric signal.

Summing up, on the basis of the available technologies, it is possible to shorten the time of the radar remaining on radar picket even to less than 60 seconds (one minute): about $10 \mathrm{~s}$ of electromagnetic radiation, about $5 \mathrm{~s}$ for radar folding, about $45 \mathrm{~s}$ for a drive of more or less $60 \mathrm{~m}$ (with the speed of about $5 \mathrm{~km} / \mathrm{h}$, i.e. about $1.4 \mathrm{~m} / \mathrm{s}$ ).

\section{Immunity AgAinst ATtACK}

The inside of the radar is sheathed by a soft thin metal sheet (about 1.5-2 mm), under which a delicate but complex web of wire-wrap conjunctions are located. Such fragile conjunctions, as well as equally fragile other subassemblies need protection - the inside of a radar is composed entirely of very breakable elements. At present, even the immediate reaction of the radar personnel to the detected anti-radiation missile will not protect the radar against the consequences of an attack. Therefore, in order to survive, the radar must be lightly armored.

The armor should not protect only some of the main subassemblies, just like in the case of some radars now in existence (e.g. NUR-21, NUR-22, Piranha 740 - Giraffe), but it should also shield the fragile subassemblies of the antenna (radiating elements and the lifting mechanism) and the stabilizing supports.

The antenna should be protected without a break while operating. The parameters of an armor plate able to protect the mechanism against splinters of the AGM-88C HARM are well known $(6.35 \mathrm{~mm})$. Apart from an armor plate, other lighter materials can be used to protect a radar antenna (Kevlar, composites with ceramic antiballistic layers, reactive armor, armors of the Chobham type).

The armoring should be as lightweight as possible and located at the rear side of the antenna, lifting and rotating together with it while operating in combat. Having detected an anti-radiation missile, the antenna must be automatically turned with its armored side towards the nearing missile and it must start to "drop". In the moment of explosion splinters of the missile exploding a few meters above the ground will hit the armor, leaving the antenna protected, regardless of its type (headlight antenna, phased array antenna or active antenna). The best solution would be ultimately to hide the antenna inside the armored vehicle and the antenna armor itself would shield it from above.

\section{Height of the Raised Antenna}

The height of the raised radar antenna (e.g. $7 \mathrm{~m}$ for NUR-26 or $12 \mathrm{~m}$ for ESR 220 Thutlwa [14]) depends, among other things, on the weight of the antenna set and its base (i.e. location of the centre of gravity), the construction of the antenna unfolding mechanism and the strength of stabilizing supports. A large, armored and stable vehicle shall serve as the best base for a radar with an antenna that could be raised very high, since the substantial multiple point stabilization of the 
TABLE I

ANTI-RADIATION MISSILES - PARAMETERS (N.D.A. - NO DATA AVAILABLE).

\begin{tabular}{|c|c|c|c|c|c|c|c|}
\hline Missile type & Ch-15P & Alarm & $\begin{array}{c}\text { Ch-32P } \\
{[\mathrm{Ch}-22 \mathrm{MP}]}\end{array}$ & $\begin{array}{l}\text { Ch-31PD } \\
\text { Ch-31PM }\end{array}$ & $\begin{array}{l}\text { Ch-58USzE } \\
\text { Ch-58USzKE }\end{array}$ & Armiger & $\begin{array}{c}\text { AGM-88 D Harm Block } 6 \\
\text { / AGM-88E AARGM }\end{array}$ \\
\hline Country & $\overline{\text { USSR }}$ & $\begin{array}{l}\text { Great } \\
\text { Britain }\end{array}$ & USSR & Russia & Russia & Germany & USA \\
\hline $\begin{array}{c}\text { Years of } \\
\text { implementation }\end{array}$ & 1988 & 1991 & $1995[1975]$ & $2002 / 2005$ & n.d.a. / 2007 & 2008 & $2003 / 2009$ \\
\hline Flight speed $[\mathrm{m} / \mathrm{s}]$ & $\begin{array}{c}1000-1100 \\
\max .1700\end{array}$ & $\begin{array}{c}320 \\
\max .695\end{array}$ & 1190 & $\begin{array}{l}600-700 / 600-700 \\
\max .1000 / \max .1170\end{array}$ & $\begin{array}{l}450-600 \\
\max .1166\end{array}$ & $\begin{array}{c}\text { n.d.a. } \\
\max .1020\end{array}$ & $\begin{array}{c}680 \\
\max .2040\end{array}$ \\
\hline Minimum range $[\mathrm{km}]$ & 40 & 8 & n.d.a. & $15 /$ n.d.a. & $10-12$ & n.d.a. & n.d.a. \\
\hline $\begin{array}{c}\text { Maximum range } \\
{[\mathrm{km}]}\end{array}$ & 150 & $45-93$ & 700 & $180-250$ / n.d.a. & 245 & 200 & $180 / 110$ \\
\hline $\begin{array}{l}\text { Maximum range } \\
\text { flight time [s] }\end{array}$ & $\begin{array}{l}150-136 \\
\min .88\end{array}$ & $\begin{array}{l}140-290 \\
\min .64\end{array}$ & 588 & $\begin{array}{l}257-416 /- \\
\min .180 /-\end{array}$ & $\begin{array}{l}544-408 \\
\text { min. } 210\end{array}$ & min. 196 & $\begin{array}{c}264 / 161 \\
\min .88 / \text { min. } 53\end{array}$ \\
\hline
\end{tabular}

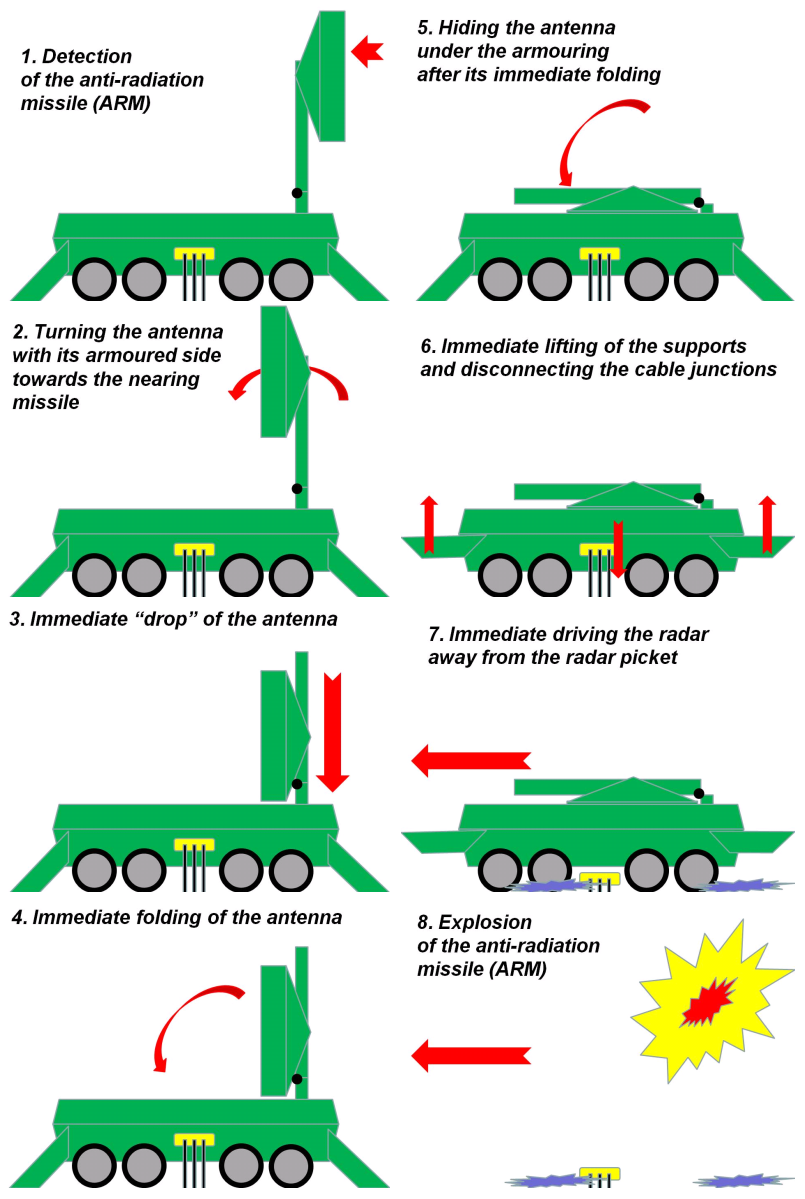

Fig. 1. Threat avoidance design for of a mid-range radar.

vehicle along with the radar together with strong stabilizing supports shall allow for operating in all kinds of terrain conditions.

\section{CONCLUSIONS}

Conclusions concerning the construction of modern radars:

- both radars and the antennas themselves should be armored;
- in a modern battlefield, it is utterly necessary to shorten the time of radar folding and its leaving of the radar picket;

- the construction of a radar should allow for operating with an antenna raised high (without the necessity of modifying the terrain, i.e. without using the embankments)[15].

\section{REQUIREMENTS}

In order to design the radar surveillance system of the $21^{\text {st }}$ century the next step that must be undertaken is a functional linking of radars. The consoles that are produced at present are able to control only some particular types of radars (e.g. RAT-31DL). As a result, such a console shall ensure control over just a fraction of the whole system, but it does not permit the complex control over the whole radar surveillance system. It has already been recognized as necessary to construct universal radar control consoles (standardization), as well as to design new radars, which would be universal within NATO in the context of standardized control. The most important requirements concerning a modern radar surveillance system include the following: high survivability (due to armoring, among others); detecting all types of air objects; supporting the tactical and operational situation analysis with the aid of "intelligent" software; full cooperation with other surveillance and command systems; module construction; possibility of controlling the radar from different levels (fully flexible operation).

The optimal use of the radar surveillance system should be based on two control levels: tactical and operational. Functional linking of the individual radars into one twolevel system will allow for gaining full control over all radar operating parameters, which, in turn, would provide full use of the system. The task of the tactical control level shall be the providing of the correct functioning of the radar surveillance system by the performance of many internal functions (e.g. maintaining a continuous detection and identification process and high survivability of the elements of the battle line). In turn, the task of the operational control level should be the controlling of the radar surveillance system by defining the parameters of its radar surveillance zone and activating individual elements of this zone, including the operation of other air surveillance systems, so that the operation time of 
the actively radiating radars could be shortened. This would lead to the limiting of the destruction of radars and facilitate their maneuvering).

Such a solution would allow the radar surveillance system to respond flexibly to the development of both the operational and tactical situation (resulting from the actual state of the Air Defense System functioning). Effective information flow within the system, as a part of the controlling process, shall, above others, allow for precise distribution of tasks to the tactical and operational level, in so far as the functioning of the radar surveillance system in the modern battlefield.

Achieving such capabilities shall also provide the possibility of the dynamic shaping of the radar surveillance zone parameters

\section{SUMMARY}

Nowadays, the existing radar surveillance systems of the Air Defense system have very little chance of surviving the first phase of a military conflict, not to mention surviving its whole duration, which was proved by the few recent ones. Therefore, it is necessary to seek new solutions in this field, which would be resistant to the destructive effects of modern combat assets.

\section{REFERENCES}

[1] http://www.ausairpower.net.

[2] http://www.airwar.ru.

[3] Raytheon - Texas Instruments AGM-88 Harm. http://www.designationsystems.net.

[4] C. Kopp, Texas Instruments - Raytheon AGM-88 Harm.

[5] W. Klembowski, J. Miłosz, T. Rutkowski, and J. Wiśniewski, "Środki ochrony radaru przed rakietami naprowadzającymi się na emisję radarową," in 43 Konferencja Naukowo - Techniczna Radiolokacji, Rynia, Polska, Nov. 2011.

[6] AGM88-HARM. http://www.globalsecurity.org.

[7] AGM-88 Harm, MS 9/07 70003Ra ed., Raytheon, 2007.

[8] US Ministry of National Defence, Defense Acquisition Management Information Retrieval, Raport nr DD-A\&T(Q\&A)823-368 nt. AGM-88E AARGM ed., 31.12.2011.

[9] D. Larratt, "Advenced anti-radiation guided missile (AARGM)," in NDIA Guns \& Missiles Conference, vol. NAVAIR Public Release 09187, Washington, USA, Apr. 2009

[10] http://polish.ruvr.ru/2012/01/31/65015571.html.

[11] S. Maślanka, Zabójcy radarów, Warszawa, 2008.

[12] Zespół Oficerów Szefostwa WRt SP, "Stacje radiolokacyjne Wojsk Radiotechnicznych Sił Powietrznych - informator." Warszawa: ZW SP, 2009.

[13] http://www.epar.pl.

[14] http://www.defenceweb.co.za.

[15] Z. Czekała, Parada radarów. Warszawa: Bellona, 1999. 